\title{
Research on Development Status and Countermeasure for Physical Learning Situation Analysis in China
}

\author{
Jianqiang Zhou ${ }^{1, a}$, Wenwei Jia ${ }^{2, b}$ \\ ${ }^{1}$ College of Education and Sports, Bohai University, Jinzhou, 121013, China \\ ${ }^{2}$ Department of Physical Education, Bohai University, Jinzhou, 121013, China \\ a909718885@qq.com, b894161757@qq.com
}

\begin{abstract}
Keywords: physical learning situation analysis; implementation points; development status; development countermeasure
\end{abstract}

\begin{abstract}
Learning analysis is an integral part of the teaching design, is the antecedent condition in effective teaching. This article from the connotation, significance and implementation points, combining with the sports teaching practice, a summary of the physical learning situation analysis development of our country the development status. Expounds the affection analysis of sports science hollow without, narrow, general, simplification of problems, and targeted from the advantages and disadvantages, the combination of multiple comprehensive analysis, runs through every link of teaching, and the lifelong development unifies, effectively integrated into the teaching process, combining practice and theory research aspects such as development countermeasures are put forward. Aims to study reasonable sentiment analysis used in physical education teaching, to realize their aptitude and treated differently, high quality to complete the teaching goal task.
\end{abstract}

\section{Introduction}

"Student-centered" concept of education has become the hot topics in the study of many researchers and sports teachers, in the hope to put the idea into reality, let each students benefit, so as to improve the effect of learning [1]. Sports as a school education as a "special" course, the responsibilities it irreplaceable. How to improve the physical education status, how to let the child like PE class, all this is closely related to students' physical education learning situation. In this paper, based on the above background, combining with the sports teaching practice, from conceptual clarity of sentiment analysis, on this basis, from the content of the situation analysis, object, method and implementation timing aspect in the sports teaching are put forward how to analysis of learning, in the hope for a line of sports teachers teaching practice to provide the reference.

\section{Connotation on Learning Situation Analysis}

Learning analysis is what is the characteristics of students in learning, learning methods, habits, how to, how interested, how, etc. Design concept including teaching methods and the research method instruction, as well as the teaching idea [2]. Learning sentiment analysis is the basic link of teaching activities, is also the basic content of teaching and research. Broadly speaking, learning situation analysis is in the "class", "class", "class" of students, the teachers "teaching" to promote the students' learning. Through the analysis of the learning before teaching, teachers can fully understand the student, for the teaching content of choice, the choice of teaching methods, and indicate the basic way to determine the starting point of teaching direction; Teaching real-time learning in the process of analysis can be for teachers to adapt and improve the teaching activity, promoting the teaching effective generated to provide important basis; And through the analysis of the learning mood after the teaching, teachers can know reach situation teaching, promote teaching after reflection, and for the subsequent teaching preset and adjustment to provide important information. 


\section{Great Significance on Learning Situation Analysis}

Learning significance analysis include the following:

(1) The learning situation analysis is the basis of the teaching goal setting. Didn't study the teaching aim of sentiment analysis is often a castle in the air, only really understand the students' existing knowledge experience and cognitive psychological characteristics, to determine its in different areas, different disciplines, and in different learning activities, the zone of proximal development from aspects of the knowledge, skills, and ability to expound scientifically and establish the teaching goal.

(2) The learning analysis based on the analysis of the teaching content. Learning classroom teaching is the preset first must focus on one aspect, carries on the teaching design, only to grasp the teaching goal and content, analysis of curriculum standard and teaching material is not enough, there is no analysis of the situation of learning content analysis is often don't have, fragmented, and only for specific students, in order to correctly define the emphases and difficulties of teaching content and key.

(3) Learn the essences of sentiment analysis is a teaching activity design. The analysis of students' potential, mainly includes the students' existing knowledge base, cognitive structure, and development needs of the students' emotion; Students in the knowledge and skills, process and method, study habits, emotions, attitudes and values of participation, state, etc. Effective classroom teaching activity design must be based on a deep and specific analysis of the students, focus on learning, for the change of the learning development of teaching to flexible organization [3].Only accurately grasp the students real learning state, appropriate and reasonable to determine the level of the teaching content, classroom discussion of the core issues and key point, can promote students' effective learning and active development.

(4) Learning situation analysis is essential for implementation of new curriculum concept. Traditional preparation also have the analysis of learning, but usually the learning analysis simple, such as: the analysis of the learners' cognitive basis simply understood as a list of knowledge points, not a concrete analysis of each class of students in the face of the new teaching content is what kind of knowledge structure, there may be any difficulties and obstacles, more not thinking about solving countermeasures. Under the background of new curriculum, based on analysis of the concept of effective teaching learning more stressed to be born, to attach importance to students' feedback on teaching, teaching with pertinence and maneuverability. Therefore, learning analysis to infiltrate the teaching design thought, become open guarantee of teaching design.

\section{Implementation Points on Learning Situation Analysis}

Learning analysis implementation points include the following:

(1) The learning analysis must pay attention to the stage. Learning is a relatively stable during a certain period of students' learning in some cases, it is constancy. Sentiment analysis should be started in the beginning of the semester teaching plan stage, embodied in the teaching plan, sometimes forming certain written words. In addition, to a certain stage of teaching, such as a unit at the end of the teaching work, a big week work summary, it is necessary to learn sentiment analysis, judgement to know students situation, adjust the next stage in the organization of teaching content, teaching goal formulation and the design of teaching activities [4].

(2) The learning analysis to maintain flexibility. Sentiment analysis is not only teaching need to be aware of the problems in the process of design, more should be throughout the whole of the classroom teaching. In classroom teaching, the students need instant, moments of learning situation more teachers discovery, analysis and use them at any time. Classroom teaching, and many times the student's behavior is not in accordance with the design intent of the teacher, the teacher wants to look, listen and understand the original understanding, students find the best in students creative, so as to adjust the teaching goal, teaching process, teaching problem, instant for secondary planning, follow the students' thought of inquiry. 
(3) Learning analysis and teaching content should be closely integrated. Learning is not isolated analysis the student union, not what, but should be combined with the teaching content targeted for analysis. To a wide range of learning situation analysis, the key is to seize the close relation with teaching contents and teaching task characteristics, especially the students master the skill level. Analysis of learning determines the choice of teaching content, the determination of heavy difficulty, only based on the accurate analysis of teaching materials and students, can choose teaching methods, design match students demand, and constantly adjust and optimize the teaching in the teaching process design, truly implement the "hierarchical requirements, respect difference, to learn to teach, according to a study teaching" the thought and strategy, to maximize the benefit of classroom teaching.

(4) Learning analysis to each link of teaching. Sentiment analysis runs throughout the teaching of each link, including the preparation, preparation activities in the daily teaching activities, class, game, games, students and teachers to practice (including collective practice, group practice, personal practice), counseling directors (including collective, group and individual guidance), teaching evaluation and so on. In preparation, teaching design, want to learn to analysis to refine the teaching goal, efforts to seek for their own learning classroom teaching fitness, in order to prepare the teaching resources [5]. In the process of teaching, in addition to through the normal class before the test to further grasp the learning, decided to the starting point of class teaching, should also be stressed and timely feedback. In addition, classroom tests and games also is an important part of the understanding of learning in classroom teaching.

\section{Development Status on Physical Learning Situation Analysis in China}

Current situation of the development of our country physical learning situation analysis is as follows:

(1) Physical analysis "of the situation of" empty. "Empty" means there should be and actually have no content. After investigation, the sports teachers' attention to the teaching material is far greater than the attention to students, students and teaching materials in the mind of physical education teachers in different sequences of value.PE teachers on the key consideration is how to combine teaching material symbolization of knowledge to students, and make students master textbook knowledge through a variety of teaching activities. Here is the remains of heavy knowledge system, taught in the traditional thinking, but can't play to the subjectivity of the students, teaching design has lost its pertinence and suitability.

(2) Physical learning situation analysis narrow. Most sports lesson plans the learning analysis reference only to determine the three-dimensional goals in the new, around the knowledge and ability, emotional attitude values to analyze the situation of the students, obviously too narrow [6].However, physical learning situation analysis content range is very wide, in addition to the new curriculum reform mentioned in the $3 \mathrm{~d}$ object, and the students' physical characteristics, social characteristics, and physical learning situation analysis science cannot be ignored for students to grasp the social features.

(3) Physical learning situation analysis science. physical learning situation analysis to students of different age stages of the macro analysis, also want to the same age stage of the student to carry on the microscopic analysis, specific to the analysis of each student. Is to analyze the learning of physical education teachers in the teaching plans generally only stay at a certain age, or stay in one class.

(4) Physical learning situation analysis simplification. On the analysis of learning based on physical education teachers is too single, basically all is the physical education teachers from one's own teaching experience and the speculative conclusions [7]. The focus on learning, physical education teachers tend to give students the advantages and advantages of more attention, and different students in different stages of learning what will encounter difficulties, the causes of difficult what little attention. 


\section{Development Countermeasure on Physical Learning Situation Analysis in China}

According to the above research, combining previous research results, puts forward some countermeasures for developing sports learning analysis in our country is as follows:

(1) The sports situation analysis to students' advantages and disadvantages, the combination of avoiding one-sidedness. Based on the analysis of learning, learn to love is a common phenomenon analysis highlights students lack too much. Emphasize the lack of students, often lies in looking for student demand, lack of teachers, then students and student demand for direction and goal of physical education teaching. Blindly analysis of students, however, neglected student's advantage, will only make the situation analysis of sports science becomes more partial, single. To avoid one-sidedness, besides combining students advantages and disadvantages in the sports learning analysis, still need to consider the problem of universality and individuality. As the same age, same class's and grade's student, they must exist in the study in common. At the same time, influenced by various factors, each student has a distinct personality. Therefore, attaches great importance to the common physical education teachers, help to control the learning on the whole, more widely meet the demand of students; Is advantageous to the teacher in the classroom teaching according to their aptitude; More conducive to teaching content for development, reuse again.

(2) The physical learning situation analysis associated with the teaching content, from the "pure". In physical learning situation analysis, a common phenomenon is too "pure" sports learning situation analysis. The meaning of the "pure" mainly for copying teachers reference book or other counselling on learning; Are not specific, no real content, nonsensical sentiment analysis. Such a physical learning situation analysis though to some extent, reflects the real situation of the student, but from the perspective of the physical education teaching design is unreasonable and unscientific. From sports teaching content analysis of the "pure" sports learning, can't play to the role of the situation analysis of sports science should have, can only become the decoration of the physical education teaching design, also cannot according to the results of situation analysis of sports science, physical education teachers do a good job in sports teaching design. As a result, the sports sentiment analysis associated with the teaching content, targeted.

(3) The analysis of the situation of sports science should by one-off to continuous multiple comprehensive analysis. Physical education teachers have realized the importance of learning situation analysis, so for personal planning, collective lesson preparation time first thing to do, you should learn love is analyzed.PE teachers every lesson to combine carefully each student's personality characteristics and the class of common traits, combining with the teaching contents, teaching space, teaching equipment and education object's age, gender, regional, ethnic, basic skills, the differences between the physical qualities and so on factors synthetically, comprehensive, in-depth and meticulous, dynamic, develop geological considerations and analysis [8]. Only in this way can truly effective to improve the teaching quality of physical education, optimize the efficiency of the teaching process; Make the physical education teaching truly targeted, according to their aptitude, improve the occasion, for learning; Make the physical education teaching really fun, and able to learn, practice and practice combined with organic speaking guide.

(4) The physical learning situation analysis each link of teaching. As a good sports teacher, in preparation, preparation activities in the daily teaching activities, class, game, games, students and teachers to practice (including collective practice, group practice, personal practice), coaching directors (including collective, group and individual guidance) on learning and teaching evaluation. In preparation, teaching design, want to learn to analysis to refine the teaching goal, efforts to seek for their own sports classroom learning teaching relevancy, and to form a complete set of teaching resources [9]. In the process of sports teaching, to students' actual stimulate their interest in learning the analysis and control. At the same time, targeted tutoring after class and to promote the development of students' evaluation should also be based on the learning situation. Learning evaluation is found, diagnosis teaching problems, effectively control the teaching process, deep control learning, further improve the teaching work of the important measures. So in the sports classroom teaching, can through appropriate classroom tests and competition in the form of a focus on learning, and learning together analysis and adjustment of teaching strategies. 
(5) The physical learning situation analysis to student's lifelong development. Investigation and analysis of sports learning is the current reform of physical education teaching, the important measure to implement effective physical education teaching. Physical education teachers in knowledge teaching, will cooperate with the experiences of the students first, do proper organization will be granted by the teaching material, make sure every student can learn knowledge; The difficulty of the teaching material and logical order, must according to the students' mental development level and make appropriate arrangements cognitive representation [10].So that continuity is the student's knowledge, so as to produce positive transfer of learning.

(6) Situation analysis of sports science should be effectively integrated into the teaching process. In the actual teaching practice, most of the physical education teachers to learn analysis processing into a single part in preparing, the fragmentation and the connection between the teaching design and teaching content arrangement. Some on the analysis of the physical education teachers "learning difficulties", from the overall analysis of the gap between students and content of the distance, but in the process of its design could see no physical education teachers in order to reduce the distance between students and the learning content and specific measures, the classroom is still the step-by-step learning content to teach. Physical education teachers is an initially from respect the principal position of students set out to analysis, to improve model, preparing but it is difficult to melt it into the phenomenon in the process of teaching. Therefore, PE teachers should be effective to learn analysis into the teaching process.

(7) Physical learning situation analysis practice should be combined with education teaching theory research. From existing research results show that the analysis of the situation of sports science starting from sports practice, most of the lack of theoretical guidance of the system. Sports teachers know how to use practical knowledge to analysis, but how to analyzing real situation of sports science in the service of sports classroom teaching effectively, it also needs education teaching theory knowledge to grope and discussed. A line of sports teachers, therefore, if you can stand in students "position" in the role of the perspective-taking, applying the relevant theory of education teaching situation analysis, summary analysis of the situation of learning actively concrete policies and laws, improve the learning analysis theory, and to guide physical education teachers in the education teaching practice analysis learning behavior, to test the effectiveness of the analysis of the situation of learning, realize the learning analysis the integration of theory with practice, it will be a meaningful things.

\section{Conclusion}

Learning situation analysis is the essences of selection of teaching strategies and the design of teaching activities, is the basis of complete teaching goal, only really understand the students' existing knowledge and psychological cognitive characteristics, in order to effectively achieve their aptitude in the teaching, the distinction between, high quality to achieve the teaching goal. In the process of sports teaching in the future, PE teachers should be adhering to the "to learn teaching", "shun learning guide teaching" the education of new ideas to make learning situation before class, class school situation analysis and the analysis of learning after class, make the "student-centered" education thought really implement into daily education teaching practice.

\section{Acknowledgement}

This work is supported by general subject of "the Twelfth Five-year Plan" on educational science of Liaoning province: Practice Research on Monitoring Evaluation System of Building Sunshine Sports Activities for Ordinary Colleges and Universities, 2015, Approval (JG15DB023). 


\section{References}

[1] M. Q. Xu, "Analysis on the learning situation in physical education teaching," Wushu Science, vol. 9, no. 6, pp. 85-90, 2012.

[2] Baidu Encyclopedia, "Learning situation analysis," http://baike.baidu.com/link?url=XkTPFhreLqbN4dSbBvpBxi9GEnfzvdgIe0edv6Sj7l3CLe-rlEz eh45D0eiAOVaePMMbgcCVxLUgfaXTJVHOkK, 2016-1-2.

[3] M. Li, "Analysis of learning situation in instructional design: significance, problems and strategies for improvement," Journal of Huaiyin Institute of Technology, vol. 21, no. 6, pp. 74-76, 2012.

[4] X. J. Qian, "Analysis of learning situation: the core and key of effective teaching," Research and Review on Education, vol. 1, no. 8, pp. 14-17, 2009.

[5] C. Y. Shao, W. Q. Zhu, "In the case study to carry out learning situation analysis," Journal of the Chinese Society of Education, vol. 35, no. 2, pp. 73-76, 2015.

[6] S. X. Gao, "Do a good job of learning situation analysis to improve the efficiency of Physical Education Teaching," Read and Write Periodical, vol. 12, no. 5, pp. 156-157, 2015.

[7] S. J. Qiu, P. F. Zheng, "My opinion on the analysis of Physical Education Teaching," China School Physical Education, vol. 30, no. 5, pp. 24-26, 2011.

[8] Y. L. Wang, "Analysis of physical education and psychological consultation," Journal of Puyang Vocational and Technical College, vol. 25, no. 3, pp. 116-117, 2012.

[9] W. J. Ma, J. S. Bao, "Analysis of learning situation: function, content and method," Educational Science Research, vol. 23, no. 9, pp. 52-57, 2013.

[10] W. D. Shao, "How to carry on the analysis in the physical education teaching design," Teaching of Physical Education, vol. 18, no. 4, pp. 36-38, 2011. 